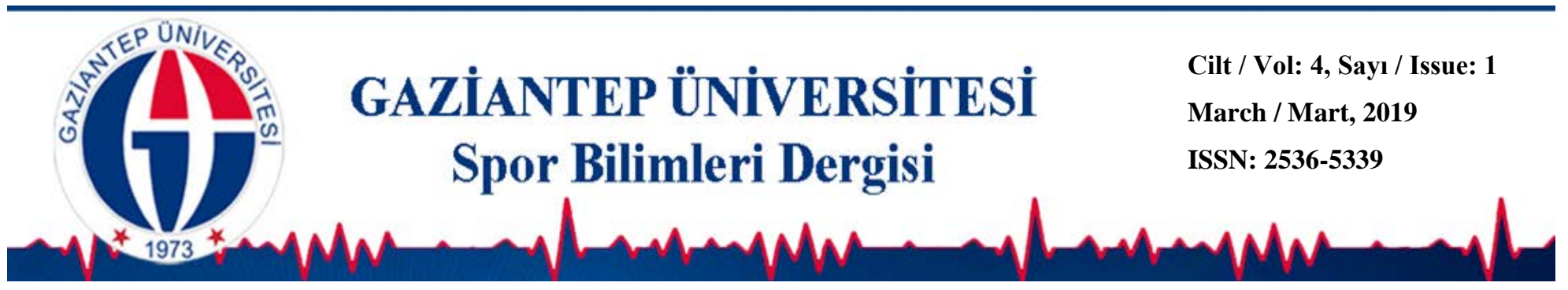

\title{
Hakemlerin Problem Çözme Becerileri İle Öz Yeterlikleri Arasındaki İlişkinin İncelenmesi
}

\author{
Aydın KARAÇAM ${ }^{1 *}$ Atilla PULUR ${ }^{2}$ \\ ${ }^{1}$ İstanbul Aydın Üniversitesi, Spor Bilimleri Fakültesi, İSTANBUL \\ ${ }^{2}$ Gazi Üniversitesi, Spor Bilimleri Fakültesi, ANKARA
}

\section{DOI: 10.31680/gaunjss.519158}

\section{Orijinal Makale / Original Article}

Gelis Tarihi / Received: 29.01.2019
Kabul Tarihi / Accepted: 12.03.2019

\section{Öz}

Yapılan çalışmanın amacı, sedanter kadınlara uygulanan 8 haftalık B-fit egzersizlerinin antropometrik özellikler Çalışmanın amacı hakemlerin problem çözme becerileri ile öz yeterlikleri arasındaki ilişkinin bazı demografik değişkenlerle birlikte incelenmesidir. Çalışmanın örneklemi uygun örnekleme yöntemi ile oluşturulmuştur. Çalışmaya 2017-2018 sezonunda aktif olarak hakemlik yapan \%50'si (n:122) futbol, \%26'sı (n:62) basketbol ve \%24'ü (n:58) hentbol hakemi olmak üzere 242 kişilik hakem grubu katıımıştır. Çalışmada veri toplama aracı olarak kişisel bilgi formu, Hepler ve Peterson (1982) tarafından geliştirilen problem çözme envanteri (PÇE) ve Karaçam ve Pulur (2017a) tarafından geliştirilen hakem öz yeterlik ölçeği (HÖYÖ) kullanılmıştır. Değişkenler arası ilişkilerin belirlenmesi için Pearson Momentler Çarpımı Korelasyon Katsayısı, ikili karşılaştırmalarda t testi ve çoklu karşılaştırmalarda tek yönlü varyans analizi (ANOVA) kullanılmıştır. Yapılan analizlerde hakemlerinin PÇE toplam puanı ile eğitim düzeyleri arasında yüksek lisans mezunu hakemler lehine anlamlı fark olduğu görülmüştür $(p<$ .05). Hakemlerin HÖYÖ toplam puanı, fiziksel yeterlik, oyun bilgisi ve baskı alt boyutu ile hakemlik branşları arasında anlamlı farklılık bulunmuştur. Hakemlerinin PÇE toplam puan ile yaşları ve hakemlik yılları arasında negatif yönlü ve anlamlı ilişki olduğu görülmüştür $(p<.05)$. Hakemlerinin HÖYÖ toplam puan, fiziksel yeterlik, oyun bilgisi, karar verme, baskı ve iletişim puanları ile yaş ve hakemlik yılları arasında pozitif yönlü ve anlamlı ilişki olduğu görülmüştür $(p<.05)$. Hakemlerin PÇE toplam puan ile HÖYÖ toplam puan fiziksel yeterlik, oyun bilgisi, karar verme, baskı ve iletişim değişkenleri negatif yönlü ve anlamlı ilişkili oldukları görülmektedir $(p<.05)$.

Anahtar Kelimeler: Futbol Hakemi, Basketbol Hakemi, Hentbol hakemi, Problem çözme, Öz yeterlik

\footnotetext{
* Sorumlu Yazar: Aydın KARAÇAM
}

E-mail: aydinkaracam@gmail.com 
Karaçam, A., Pulur, A. (2019). Hakemlerin Problem Çözme Becerileri İle Öz Yeterlikleri Arasındaki İlişkinin İncelenmesi. Gaziantep Üniversitesi Spor Bilimleri Dergisi, 4(1), 115-130.

\title{
Examining the Relationship Between Referees' Problem Solving Skills and
}

\section{Their Self-Efficacy}

\begin{abstract}
The aim of the study is to examine the relationship between referees' problem-solving skills and their self-efficacy by certain demographic variables. The sample of the study was formed by convenience sampling method. A total of 242 referees, including 50\% $(n=122)$ soccer referees, $26 \%(n=62)$ basketball referees and $24 \%(n=58)$ handball referees, participated in the study. The participants served as official referees in the 2017-2018 season. In the study, a demographic information form, the Problem-Solving Inventory (PSI) developed by Hepler and Peterson (1982) and the Referee Self-Efficacy Scale (REFS) developed by Karaçam and Pulur (2017a) were used as data collection tools. Pearson Product-Moment Correlation Coefficient was used to determine the relationships between the variables; T-Test was used for paired comparisons and One-Way Analysis of Variance (ANOVA) was used for multiple comparisons. A significant difference was found between PSI total score and referees' levels of education in favor of master's graduates $(p<.05)$. A significant difference was found between REFS total score, and sub-scales of the REFS, which are physical fitness, game knowledge and pressure, and referees' branches. There was a negative significant relationship between PSI total score and referees' ages and refereeing experience $(p<.05)$. A positive significant relationship was found between REFS total score and subscales of the REFS, which are physical fitness, game knowledge, decision making, pressure and communication, and referees' ages and refereeing experience $(p<.05)$. PSI and REFS total scores and sub-scales of the REFS, which are physical fitness, game knowledge, decision making, pressure and communication were found to be negatively and significantly correlated $(p<.05)$.
\end{abstract}

Keywords: Soccer Referee, Basketball Referee, Handball Referee, Problem-solving, Self-efficacy

\section{Giriş}

Bir hakem, müsabaka sırasında görevini başarıyla yerine getirmek ve kararlarında hata yapmamak için baskı altında birden fazla görevi yerine getirmelidir. Örneğin, hakemler, olumsuz koşullar ve baskı altında, maç sırasında gerçekleşen eylemleri değerlendirmeli ve yargılamalı, hızlı kararlar almalı, oyunu yönetmeli, doğru iletişim kurmalı, oyunun birden çok yönüne dikkat etmeli, düzenini sürdürmeli, anlaşmazlıkları ve problemleri çözmelidir (Karaçam ve Pulur, 2016; Tuero ve ark., 2002). Bu görevlerdeki yetersizlik, dikkatsizlik, yanlış kararlar, gecikmeli tepkiler, nihai stres ve tükenmişliğe yol açabilir (Ekmekçi, 2008; Ekmekçi, 2016a; Ekmekçi, 2016b; Guillén ve Feltz, 2011). Ayrıca hakemler özellikle popüler spor branşlarında müsabaka öncesi, sırası ve sonrasında seyirci, oyuncu ve kulüp baskısına maruz kalmaktadırlar. Bu nedenle hakemlerin yaptıkları iş oldukça zor ve yıpratıcıdır. Bunun yanında yaşam boyunca, bireylerin maruz kaldıkları olumsuz koşullara ve ortama uyum sağlama çabaları duygusal stresin oluşmasına da sebep olabilir (Sivrikaya, 2018). Hakemler tüm bu olumsuz etkenlere rağmen güçlü bir karakter ve başarılı bir performans göstermek zorundadır (Karaçam ve Pulur, 2018b).

Hakemin sahada karar verme sürecini sadece sahadaki performansın niteliği belirlemez, bunun yanında seyircilerin, antrenörlerin, yöneticilerin ve oyuncuların baskısı ve davranışları da belirler. Bir hakemin böyle durumlarda doğru karar verebilmesi için kendini sürekli geliştirmesi gerekir (Cel, 1994). Bir hakemin fiziksel performansı üst seviyede olsa dahi sahada sürekli değişen koşullara karşı 
alternatifler üretmesi gerekir. Bu değişen koşullar oyuncu, antrenör, yönetici ve seyircilerin olumsuz davranışlarından ve hakemi psikolojik olarak baskı altına almak istemelerinden kaynaklı oluşabilir. Bunun yanında hakemlerin kendi aralarında oluşabilecek anlaşmazlıklardan da kaynaklanabilir (Ekmekçi, 2008). Müsabaka sırasında değişen bu koşullar hakemin çözmesi gereken problemler olarak karşısına çıkmaktadır. Müsabaka sırasında karşılaşılan problemlerin uygun biçim ve süreçler içerisinde çözümlenmesi, üst düzey hakem performansı açısından önemlidir. Bir hakem problemi görme, tanımlama ve çözme sürecini mümkün olan en kısa sürede tamamlamalıdır (Taylan, 1990). Bu sayede oyunun akıcılığını sağlayarak daha heyecan verici olmasına katkı sağlar.

Bu bağlamda problemlerin çözümünde problemlere nasıl yaklaşıldığı önem kazanmaktadır. Problemlere pozitif yaklaşma ve oyunun paydaşlarıyla olumlu iletişim kurma problemlerin çözümünde etkili bir yöntem olarak düşünülebilir (Tutar,2001). Yapılan bazı çalışmalarda hakemlerin pozitif inançlarının onların problem çözme becerilerini olumlu yönde etkilediği sonucuna ulaşımıştır(Efe, Öztürk ve Koparan, 2008; Ekmekçi, 2016b; Karaçam ve Pulur, 2016). Ayrıca hakemlerin bazı pozitif inançlarının onların performanslarına olumlu yönde etki ettiği sonucuna da ulaşıImıştır (Guillén ve Feltz 2011; Karaçam ve Pulur 2016; Karaçam ve Pulur 2017b; Karaçam ve Pulur 2018a; Myers vd. 2012). Alan yazındaki çalışmalardan hareketle hakemlerin problem çözme becerilerini etkileyen değişkenlerin bilinmesinin hakem performansı açısından da önemli olduğu söylenebilir. Bu bağlamda çalışmada hakemlerin problem çözme becerilerini etkileyeceği düşünülen pozitif psikoloji değişkenlerinden öz yeterlik ele alınmıştır.

Hakem öz yeterliği, Bandura'nın öz yeterlik teorisi (Bandura, 1997) ve daha özel olarak sporda öz yeterlik içinde kavramsallaştırımıştır (Feltz vd., 2008). Öz yeterlik, bazı durumsal talepler göz önüne alındığında bir kişinin belli bir alanda istenen sonuçları doğurabilecek gerekli davranışları başarıı bir biçimde yapabileceğine olan inancı ve performansın farklı düzeylerini başarıyla yerine getirebilme yeteneği olarak tanımlanmaktadır (Bandura, 1977, Bandura 1986). Hakem öz yeterliği ise hakemlerin işlerinde başarıı bir şekilde performans kapasitesine sahip olduklarına yönelik inanç derecesi olarak tanımlanmıştır (Guillén ve Feltz 2011). Guillén ve Feltz (2011), Myers ve ark., (2012) ve Karaçam ve Pulur (2017a) hakem öz-yeterlik alanlarının oyun bilgisi ve stratejik beceriler, karar verme becerileri, psikolojik beceriler, oyunun iletişimi, denetimi ve fiziksel uygunluk olarak 
belirtmişlerdir. Ayrıca Guillén ve Feltz (2011) kendi kendini yeterlik teorisinden ve sporda öz yeterlik araştırmasından yola çıkarak, öz yeterliği yüksek hakemlerin kararlarında daha doğru ve performanslarında daha etkili olduklarını belirtmişlerdir. Bunun yanında antrenörlerden, yöneticilerden ve diğer yetkililerden daha fazla saygı gördükleri ve öz yeterliği düşük hakemlere göre daha az stres yaşadıklarını belirtmişlerdir. Ayrıca Guillén ve Feltz (2011) ve Farshad vd. (2013) öz yeterliği yüksek hakemlerin mesleğe daha fazla bağlı olduklarını ve bu durumun hakemlik performansını olumlu yönde etkilediğini belirtmişlerdir. Hepler ve Feltz (2012) yaptıkları çalışmada öz yeterlik düzeyinin karar vermede önemli bir etkisinin olduğunu bu durumunda hakem performansını olumlu yönde etkilediğini belirtmişlerdir. Ayrıca Myers ve ark., (2012) ve Karaçam ve Pulur (2017a), Karaçam ve Pulur (2017b), Karaçam ve Pulur (2017c), Adıgüzel (2018) ve Karaçam ve Adıgüzel (2019) yaptıkları çalışmalarda hakemlerin öz yeterlik düzeyleriyle yaşları ve hakemlik tecrübeleri arasında pozitif yönlü bir ilişki bulmuşlar ve hakemlerin yaş ve deneyimleri arttıkça öz yeterlik düzeylerinin de arttığını belirtmişlerdir. Spencer (2015) yaptığı çalışmada hakemlerin performanslarının en önemli yordayıcısının tecrübe olduğunu belirtmiştir.

Yukarıda incelenen araştırmalardan yola çıkıldığında futbol, basketbol ve hentbol hakemlerinin problem çözme becerileri ile hakem öz yeterliğini etkileyen değişkenlerin ve bu değişkenler arasındaki ilişkilerin bilinmesi hakem eğitim sürecinin planlanmasında, müsabakaların başarılı bir şekilde yönetilmesinde ve hakem performansının yükseltilmesinde oldukça önemli olduğu görülmektedir. Alan yazın incelendiğinde hakemlerin problem çözme becerileri ile öz yeterliklerini birlikte ele alan bir çalışmaya rastlanamamıştır. Bu nedenle bu çalışmada futbol, basketbol ve hentbol hakemlerinin problem çözme becerileri ile öz yeterlik düzeyleri arasındaki ilişki bazı demografik değişkenlerle birlikte incelenmesi amaçlanmıştır.

\section{Yöntem}

\section{Araştırmanın Modeli}

Hakemlerin problem çözme becerileri ile öz yeterlikleri arasındaki ilişkiyi bazı demografik değişkenler açısından incelenmesini amaçlayan bu çalışma ilişkisel tarama modelinde betimsel bir çalışmadır. İlişkisel çalışmalar her ne kadar gerçek anlamda bir nedenselliğin varlığını kanıtlamasa da bazı ileri düzey istatistik 
Karaçam, A., Pulur, A. (2019). Hakemlerin Problem Çözme Becerileri İle Öz Yeterlikleri Arasındaki İlişkinin İncelenmesi. Gaziantep Üniversitesi Spor Bilimleri Dergisi, 4(1), 115-130.

tekniklerinin kullanılmasıyla ilişkisel çalışmalarla neden-sonuç ilişkisine yönelik çıkarımlarda bulunmak mümkün olabilmektedir (Fraenkel ve Wallen, 2009).

\section{Evren ve Örneklem}

Bu çalışmanın evrenini 2017-2018 sezonunda futbol, basketbol ve hentbol branşlarında aktif olarak hakemlik yapan saha hakemleri oluşturmuştur. Çalışmanın örneklemi uygun örnekleme yöntemi ile oluşturulmuştur. Ulaşılabilirlik ve elverişlilik esasına dayalı olan uygun örnekleme yöntemi bazı araştırma konularında bilgilerin hızlıca toplanması amacıyla tercih edilen bir yöntemdir (Büyüköztürk, 2010). Uygun örnekleme yöntemiyle seçilen 242 kişilik grubun \%50'si (n:122) futbol, \%26'sı (n:62) basketbol ve \%24'ü (n:58) hentbol hakemidir. Çalışmaya katılan hakem grubunun \%16,5'ini (n:40) kadın, \% 83,5'ini (n:202) erkek hakemler oluşturmaktadır. Çalışmaya katılan hakemlerin yaş ortalanması 29 , hakemlik tecrübeleri ortalama 7 yıldır.

\section{Veri toplama araçları}

Çalışmada veri toplama aracı olarak kişisel bilgi formu, Hepler ve Peterson (1982) tarafından geliştirilen problem çözme envanteri (PÇE) ve Karaçam ve Pulur (2017a) tarafından geliştirilen hakem öz yeterlik ölçeği (HÖYÖ) kullanılmıştır. Çalışmaya katılan hakemlere ölçme araçları online anket formu kullanılarak mail yoluyla uygulanmıştır.

\section{Hakem Öz Yeterlik Ölçeği (HÖYÖ)}

Hakem Öz Yeterlik Ölçeği (HÖYÖ) ilk olarak 2012 yılında Myers vd. tarafından geliştirilmiş. Fiziksel yeterlik faktörü eklenmiş Türkçe versiyonu Karaçam ve Pulur (2017a) tarafından yapılmıştır. Ölçeğin beşli likert tipi dereceleme biçiminde oluşturulmuş 18 maddesi bulunmaktadır. Ölçekte 5 maddeden oluşan fiziksel yeterlik, 3 maddeden oluşan oyun bilgisi, 3 maddeden oluşan karar verme, 3 maddeden oluşan baskı ve 4 maddeden oluşan iletişim olmak üzere dört alt faktörü vardır. Ölçekte ters puanlanan madde bulunmamaktadır. Ölçeğin her bir faktöründen alınan yüksek puanlar, o faktördeki öz yeterliğin yüksek olduğunu göstermektedir. Tüm ölçek için açıklanan varyansın \%72.27 olduğu görülmüştür. Öz değerleri 1'den büyük beş bileşenli bir yapı ortaya çıkmıştır. Ölçek bileşenleri için alfa iç tutarlık katsayılarının fiziksel yeterlik faktöründe .88, oyun bilgisi faktöründe .71, karar verme faktöründe .85 , baskı faktörü .88 , iletişim faktöründe .81 ve ölçeğin tümü için .90 
olduğu görülmüştür. KMO değerinin ise .86 olduğu görülmüştür. Ölçeğe uygulanan DFA analizi sonucunda $\chi^{2} / \mathrm{sd}=1.842 \mathrm{RMSEA}=.06, \mathrm{CFI}=.94, \mathrm{GFI}=.88, \mathrm{RMR}=.01$ olduğu görülmüştür.

\section{Problem Çözme Envanteri (PÇE)}

Hepler ve Peterson (1982) tarafından geliştirilen ölçek bireyin problem çözme becerileri konusunda kendi anlayışını ölçmektedir. 35 maddeden oluşan ve 1-6 arası puanlama sistemine göre değerlendirilen Likert tipi bir ölçektir. Ölçekten alınan toplam puanların yüksekliği, bireyin problem çözme becerileri konusunda kendini yetersiz olarak algıladığını göstermektedir. Puanlama sırasında 9., 22. ve 29. maddeler protokole uygun olarak puanlama dışı tutulmuştur. 1., 2., 3., 4., 11., 14., 15., 17., 21., 25., 26., 30., ve 34. maddeler ters olarak puanlanmıştır. Maddelerin problem çözme becerilerini yeterli oranda temsil ettiği varsayılmıştır. Puanlama aralığı 32-192 arasındadır. Ölçeğin iç tutarlık katsayısı Cronbah Alfa: .88 ve test yarılama yöntemi ile yapılan güvenirlik katsayısı ise .81 olarak bulunmuştur.

\section{Verilerin analizi}

Verilerin çözümlenmesi SPSS 21 programları kullanılarak yapılmıştır. Verilerin analizinde öncelikli olarak veri seti hatalı değer, aykırı değer ve çoklu bağıntı açısından incelenmiştir. Bu süreçte hatalı olarak girilen veri olmadığı gözlenmiştir. Dağılımın normalliği Shapiro Wilk testi ile incelenmiştir. Eldeki verilerin normal dağılıma sahip olduğu görülmüştür $(p>$.05). Futbol, basketbol ve hentbol hakemlerinin mesleki haz düzeyleri ile cinsiyete ve eğitim durumu göre farklıı̆ın analizinde $t$ testi, branşa göre farklıı̆ı̆ın analizinde çoklu varyans analizi (ANOVA) kullanılmıştır. Futbol, basketbol ve hentbol hakemlerinin yaş ve kıdem değişkenleri ile PÇE ve HÖYÖ puanları arasındaki ilişki Pearson Momentler Çarpımı Korelasyon Katsayısı ile incelenmiştir. Anlamlılık düzeyi $p<.05$ alınmıştır. 


\section{Bulgular}

Tablo 1. Futbol, basketbol ve hentbol hakemlerinin PÇE VE HÖYÖ düzeylerinin cinsiyete göre t-testi sonuçları

\begin{tabular}{|c|c|c|c|c|c|c|c|}
\hline \multirow[t]{2}{*}{ Değişkenler } & \multicolumn{2}{|c|}{$\begin{array}{l}\text { Kadın } \\
(n=40)\end{array}$} & \multicolumn{2}{|c|}{$\begin{array}{c}\text { Erkek } \\
(n=202)\end{array}$} & \multirow[t]{2}{*}{$t$} & \multirow[t]{2}{*}{$s d$} & \multirow[t]{2}{*}{$P$} \\
\hline & $\overline{\mathrm{x}}$ & $S$ & $\overline{\mathrm{x}}$ & $S$ & & & \\
\hline PÇE Toplam & 56.11 & 8.95 & 57.08 & 8.68 & .64 & 240 & .52 \\
\hline HÖYÖ Toplam & 81.97 & 6.04 & 81.77 & 6.29 & .18 & 240 & .85 \\
\hline Fiziksel yeterlik & 21.97 & 2.48 & 22.48 & 2.62 & 1.12 & 240 & .26 \\
\hline Oyun bilgisi & 13.77 & 1.20 & 13.87 & 1.39 & .42 & 240 & .66 \\
\hline Karar verme & 13.65 & 1.52 & 13.65 & 1.45 & .03 & 240 & .97 \\
\hline Baskı & 13.95 & 1.39 & 13.81 & 1.52 & .51 & 240 & .61 \\
\hline İletişim & 18.67 & 1.67 & 18.32 & 1.82 & 1.11 & 240 & .26 \\
\hline
\end{tabular}

Tablo 1 incelendiğinde futbol, basketbol ve hentbol hakemlerinin PÇE toplam, HÖYÖ toplam puan, fiziksel yeterlik, oyun bilgisi, karar verme, baskı ve iletişim düzeyleri arasında cinsiyetlerine göre anlamlı bir fark olmadığı görülmüştür.

Tablo 2. Futbol, basketbol ve hentbol hakemlerinin PÇE VE HÖYÖ düzeylerinin eğitim düzeylerine göre t-testi sonuçları

\begin{tabular}{|c|c|c|c|c|c|c|c|}
\hline \multirow[t]{2}{*}{ Değişkenler } & \multicolumn{2}{|c|}{$\begin{array}{c}\text { Lisans } \\
(n=198)\end{array}$} & \multicolumn{2}{|c|}{$\begin{array}{c}\text { Yüksek lisans } \\
(n=44)\end{array}$} & \multirow[t]{2}{*}{$t$} & \multirow[t]{2}{*}{$s d$} & \multirow[t]{2}{*}{$P$} \\
\hline & $\overline{\bar{X}}$ & $S$ & $\overline{\mathrm{X}}$ & $S$ & & & \\
\hline PÇE Toplam & 56.42 & 8.80 & 59.18 & 8.02 & 2.02 & 240 & $.04^{*}$ \\
\hline HÖYÖ Toplam & 81.95 & 6.14 & 81.11 & 6.70 & .81 & 240 & .41 \\
\hline Fiziksel yeterlik & 22.41 & 2.44 & 22.31 & 3.24 & .22 & 240 & .82 \\
\hline Oyun bilgisi & 13.83 & 1.39 & 13.95 & 1.21 & .51 & 240 & .61 \\
\hline Karar verme & 13.66 & 1.44 & 13.61 & 1.52 & .21 & 240 & .82 \\
\hline Baskı & 13.85 & 1.51 & 13.75 & 1.46 & .43 & 240 & .66 \\
\hline İletişim & 18.43 & 1.78 & 18.13 & 1.86 & .98 & 240 & .31 \\
\hline
\end{tabular}

Tablo 2 incelendiğinde futbol, basketbol ve hentbol hakemlerinin PÇE toplam puanı ile eğitim düzeyleri arasında yüksek lisans mezunu hakemler lehine anlamlı fark olduğu görülmüştür. HÖYÖ toplam puan, fiziksel yeterlik, oyun bilgisi, karar verme, baskı ve iletişim düzeyleri arasında eğitim durumlarına göre anlamlı bir fark olmadığı görülmüştür. 
Karaçam, A., Pulur, A. (2019). Hakemlerin Problem Çözme Becerileri İle Öz Yeterlikleri Arasındaki İlişkinin İncelenmesi. Gaziantep Üniversitesi Spor Bilimleri Dergisi, 4(1), 115-130.

Tablo 3. Futbol, basketbol ve hentbol hakemlerinin PÇE VE HÖYÖ düzeylerinin branşa göre ANOVA sonuçları

\begin{tabular}{|c|c|c|c|c|c|c|c|c|c|c|c|}
\hline Değişkenler & Grup & $n$ & $\bar{X}$ & $S$ & Var. K. & KT & $s d$ & KO & $F$ & $p$ & TUKEY \\
\hline \multirow{4}{*}{$\begin{array}{l}\text { PÇE } \\
\text { toplam }\end{array}$} & 1.Futbol & 122 & 56.77 & 8.13 & & 560 & 2 & 280 & \multirow{4}{*}{.03 } & \multirow{4}{*}{.96} & \\
\hline & 2.Basketbol & 62 & 57.02 & 9.44 & Ara & 0.00 & 2 & 2.00 & & & \\
\hline & 3. Hentbol & 58 & 57.12 & 9.23 & G. İçi & 18313.49 & 239 & 76.62 & & & \\
\hline & Total & 242 & 56.92 & 8.71 & Toplam & 18319.10 & 241 & & & & \\
\hline \multirow{4}{*}{$\begin{array}{l}\text { HÖYÖ } \\
\text { toplam }\end{array}$} & 1.Futbol & 122 & 82.28 & 5.73 & G. & 65040 & 2 & 32521 & \multirow{4}{*}{8.88} & \multirow{4}{*}{$.00^{*}$} & \multirow{4}{*}{$\begin{array}{l}1-3 ; \\
2 ; 3\end{array}$} \\
\hline & 2.Basketbol & 62 & 83.46 & 5.79 & Arası & 000.45 & $<$ & $\angle 0 . \angle 4$ & & & \\
\hline & 3. Hentbol & 58 & 78.01 & 6.90 & G. İçi & 8745.37 & 239 & 36.56 & & & \\
\hline & Total & 242 & 81.80 & 6.24 & Toplam & 9395.87 & 241 & & & & \\
\hline \multirow{4}{*}{$\begin{array}{l}\text { Fiziksel } \\
\text { yeterlik }\end{array}$} & 1.Futbol & 122 & 22.41 & 1.97 & & 135.48 & 2 & 6774 & \multirow{4}{*}{10.79} & \multirow{4}{*}{$.00^{*}$} & \multirow{4}{*}{$\begin{array}{l}1-3 \\
2-1 ; \\
2-3\end{array}$} \\
\hline & 2.Basketbol & 62 & 23.41 & 1.97 & Arası & 100.40 & 2 & 01.14 & & & \\
\hline & 3.Hentbol & 58 & 21.29 & 3.08 & G. İçi & 1500.43 & 239 & 6.27 & & & \\
\hline & Total & 242 & 22.39 & 2.60 & Toplam & 1635.91 & 241 & & & & \\
\hline \multirow{4}{*}{ Oyun bilgisi } & 1.Futbol & 122 & 13.88 & 1.26 & & 1396 & 2 & 261 & \multirow{4}{*}{3.85} & \multirow{4}{*}{$.02^{*}$} & \multirow{4}{*}{$2-3$} \\
\hline & 2.Basketbol & 62 & 14.16 & 1.14 & A & & & & & & \\
\hline & 3.Hentbol & 58 & 13.48 & 1.67 & G. İçi & 433.26 & 239 & 2.27 & & & \\
\hline & Total & 242 & 13.85 & 1.36 & Toplam & 447.22 & 241 & & & & \\
\hline \multirow{4}{*}{$\begin{array}{l}\text { Karar } \\
\text { verme }\end{array}$} & 1.Futbol & 122 & 13.73 & 1.33 & & 10.52 & 2 & 6.38 & \multirow{4}{*}{2.49} & \multirow{4}{*}{.08} & \\
\hline & 2.Basketbol & 62 & 13.83 & 1.40 & & & & & & & \\
\hline & 3. Hentbol & 58 & 13.29 & 1.71 & G. İçi & 504.01 & 239 & 3.01 & & & \\
\hline & Total & 242 & 13.65 & 1.46 & Toplam & 514.53 & 241 & & & & \\
\hline \multirow{4}{*}{ Baskı } & 1.Futbol & 122 & 14.00 & 1.42 & & 1993 & 2 & 163.46 & \multirow{4}{*}{4.52} & \multirow{4}{*}{$.01^{*}$} & \multirow{4}{*}{$\begin{array}{l}1-3 ; \\
2 ; 3\end{array}$} \\
\hline & 2.Basketbol & 62 & 14.00 & 1.36 & & & & & & & \\
\hline & 3.Hentbol & 58 & 13.32 & 1.72 & G. İçi & 526.77 & 239 & 40.00 & & & \\
\hline & Total & 242 & 13.83 & 1.50 & Toplam & 546.71 & 241 & & & & \\
\hline \multirow{4}{*}{ İletişim } & 1.Futbol & 122 & 18.59 & 1.65 & & 12.13 & 2 & 28.46 & \multirow{4}{*}{1.88} & \multirow{4}{*}{15} & \\
\hline & 2.Basketbol & 62 & 18.29 & 1.83 & Arast & & & & & & \\
\hline & 3. Hentbol & 58 & 18.05 & 2.06 & & 771.12 & 239 & 13.94 & & & \\
\hline & Total & 242 & 18.38 & 1.80 & Toplam & 783.26 & 241 & & & & \\
\hline
\end{tabular}

Tablo 3 incelendiğinde, futbol, basketbol ve hentbol hakemlerinin PÇE toplam puan, karar verme ve iletişim puanları ile hakemlik branşları arasında anlamlı fark bulunamamıştır. Futbol, basketbol ve hentbol hakemlerinin HÖYÖ toplam puanı, fiziksel yeterlik, oyun bilgisi ve baskı alt boyutu ile hakemlik branşları arasında anlamlı farkılık bulunmuştur. Bu farkın hangi branşlar arasında olduğunu belirlemek için yapılan Tukey testi sonuçlarına göre futbol ve basketbol hakemlerinin hentbol hakemlerine göre HÖYÖ toplam puanlarının daha yüksek olduğu görülmüştür. Fiziksel yeterlik alt boyutu puanlarında Futbol hakemleri hentbol hakemlerinden, basketbol hakemleri futbol ve hentbol hakemlerinden daha yüksek puan almışlardır. 
Karaçam, A., Pulur, A. (2019). Hakemlerin Problem Çözme Becerileri İle Öz Yeterlikleri Arasındaki İlişkinin İncelenmesi. Gaziantep Üniversitesi Spor Bilimleri Dergisi, 4(1), 115-130.

Oyun bilgisi alt boyutu puanlarında basketbol hakemleri hentbol hakemlerinden daha yüksek puan almışlardır. Baskı alt boyutu puanlarında Futbol ve basketbol hakemleri hentbol hakemlerinden daha yüksek puan almışlardır.

Tablo 4. Futbol, basketbol ve hentbol hakemlerinin PÇE VE HÖYÖ düzeyleri ile yaş ve hakemlik yılı arasındaki korelasyon

\begin{tabular}{|c|c|c|c|}
\hline Değişkenler & $n$ & Yaş & Hakemlik yılı \\
\hline PÇE Toplam & 242 & $-.18^{* * x}$ & $-.20^{* *}$ \\
\hline HÖYÖ Toplam & 242 & $.30^{\text {*t }}$ & $.29^{* \pi}$ \\
\hline Fiziksel yeterlik & 242 & $.26^{* *}$ & $.26^{\text {** }}$ \\
\hline Oyun bilgisi & 242 & $.26^{\text {** }}$ & $.25^{* *}$ \\
\hline Karar verme & 242 & $.24^{\text {tw }}$ & $.23^{* \pi}$ \\
\hline Baskı & 242 & $.14^{*}$ & $.13^{*}$ \\
\hline İletişim & 242 & $.23^{* *}$ & $.22^{\star *}$ \\
\hline
\end{tabular}

Tablo 4 incelendiğinde, Futbol, basketbol ve hentbol hakemlerinin PÇE toplam ile yaşları $(r=-.18, p=.00)$ ve hakemlik yılları $(r=-.20, p=.00)$ arasında negatif yönlü ve anlamlı ilişki olduğu görülmüştür. Yaş ve hakemlik yılı arttıkça problem çözme envanterinden alınan puan düşmektedir. Bu durum yaş arttıkça hakemlerin problem çözme becerilerinin arttığı şeklinde yorumlanabilir. Futbol, basketbol ve hentbol hakemlerinin HÖYÖ toplam puan, fiziksel yeterlik, oyun bilgisi, karar verme, baskı ve iletişim puanları ile yaş ve hakemlik yılları arasında pozitif yönlü ve anlamlı ilişki olduğu görülmüştür. Bu durum hakemlerin yaş ve hakemlik yılı arttıkça öz yeterlik ve öz yeterlik alt boyutlarından aldıkları puanların arttığı şeklinde yorumlanabilir.

Tablo 5. Futbol, basketbol ve hentbol hakemlerinin PÇE puanları ile HÖYÖ puanları arasındaki korelasyon

\begin{tabular}{|c|c|c|c|c|c|c|c|}
\hline Değişkenler & 1 & 2 & 3 & 4 & 5 & 6 & 7 \\
\hline 1. PÇE Toplam & 1.00 & $-.30^{* *}$ & $-.22^{\star \star}$ & $-.23^{\star *}$ & $-.21^{\star *}$ & $-.13^{*}$ & $-.14^{*}$ \\
\hline 2. HÖYÖ Toplam & & 1.00 & $.65^{\star *}$ & $.78^{\star *}$ & $.74^{* *}$ & $.69^{* *}$ & $.66^{* \pi}$ \\
\hline 3. Fiziksel yeterlik & & & 1.00 & $.46^{\text {** }}$ & $.25^{\star *}$ & $.26^{*}$ & $.17^{* \pi}$ \\
\hline 4. Oyun bilgisi & & & & 1.00 & $.59^{* \pi}$ & $.47^{* \pi}$ & $.45^{* \pi}$ \\
\hline 5. Karar verme & & & & & 1.00 & $.55^{* *}$ & $.50^{* \pi}$ \\
\hline 6. Baskı & & & & & & 1.00 & $.46^{* \pi}$ \\
\hline 7. İletişim & & & & & & & 1.00 \\
\hline
\end{tabular}


Tablo 5 incelendiğinde; PÇE toplam puan ile HÖYÖ toplam puan fiziksel yeterlik, oyun bilgisi, karar verme, baskı ve iletişim değişkenleri negatif yönlü ve anlamlı ilişkili oldukları görülmektedir. PÇE ile en yüksek ilişkinin HÖYÖ toplam puan ( $r=-.30, p<.01)$, en düşük ilişkinin ise baskı arasında $(r=-.13, p<.05)$ olduğu görülmüştür. Bu durum HÖYÖ puanları arttıkça Hakemlerin problem çözme becerilerinin arttığı şeklinde yorumlanabilir.

Hakem öz yeterliği, alt boyutları ve alt boyutların birbiriyle ilişkilerinde en yüksek ilişkinin HÖYÖ toplam puanı ile oyun bilgisi arasında olduğu $(r=.78, p<.01)$, en düşük ilişkinin ise fiziksel yeterlik ile iletişim arasında $(r=.65, p<.01)$ olduğu görülmüştür.

\section{Tartışma ve Sonuç}

$\mathrm{Bu}$ çalışmada futbol, basketbol ve hentbol hakemlerinin problem çözme becerileri ile öz yeterlik düzeyleri arasındaki ilişki bazı demografik değişkenlerle birlikte incelenmesi amaçlanmıştır.

Futbol, basketbol ve hentbol hakemlerinin PÇE düzeyleri arasında cinsiyetlerine göre anlamlı bir fark olmadığı görülmüştür. Karaçam ve Pulur (2016) basketbol hakemleri üzerine yaptıkları çalışmada çalışmanın paralelinde sonuçlara ulaşmışlardır. Bu durum hakemlerin problem çözme becerilerinde cinsiyetin önemli bir değişken olmadığı şeklinde yorumlanabilir.

Futbol, basketbol ve hentbol hakemlerinin HÖYÖ toplam puan, fiziksel yeterlik, oyun bilgisi, karar verme, baskı ve iletişim düzeyleri arasında cinsiyetlerine göre anlamlı bir fark olmadığı görülmüştür. Karaçam ve Pulur (2017c) çalışmanın paralelinde basketbol hakemlerinin fiziksel yeterlik, baskı ve iletişim düzeyleri arasında cinsiyetlerine göre anlamlı bir fark olmadığını belirtmişlerdir. Karaçam ve Pulur (2017c) basketbol hakemleri üzerine yaptıkları çalışmada çalışmanın aksine erkek hakemlerin HÖYÖ toplam puanda kadın hakemlerden daha yüksek puana sahip olduğu sonucuna ulaşmışlardır. Ayrıca Karaçam ve Pulur (2017c) basketbol hakemleri üzerine yaptıkları çalışmada fiziksel yeterlik ve karar verme alt boyutlarında erkek hakemler lehine anlamlı fark olduğu sonuca ulaşmışlardır. Bu bağlamda çalışma sonuçları ilgili alan yazınla paralellik göstermemektedir. Alan yazındaki bu farklı sonuçların çalışılan grubun kendine özgü özelliğinden kaynaklandığı düşünülmektedir. 
Karaçam, A., Pulur, A. (2019). Hakemlerin Problem Çözme Becerileri İle Öz Yeterlikleri Arasındaki İlişkinin İncelenmesi. Gaziantep Üniversitesi Spor Bilimleri Dergisi, 4(1), 115-130.

Futbol, basketbol ve hentbol hakemlerinin PÇE toplam puanı ile eğitim düzeyleri arasında yüksek lisans mezunu hakemler lehine anlamlı fark olduğu görülmüştür. Karaçam ve Pulur (2017c) basketbol hakemleri üzerine yaptıkları çalışmada çalışmanın paralelinde yüksek lisans mezunu hakemler lehine sonuçlara ulaşmışlardır. Efe vd. (2008) futbol hakemleri üzerine yaptıkları çalışmada üniversite mezunu hakemlerin lise mezunu hakemlere göre daha düşük PÇE puanına sahip oldukları sonucuna ulaşmışlardır. Bu durum hakemlerin problem çözme becerilerinde eğitim durumlarının önemli bir değişken olduğu şeklinde yorumlanabilir. Bu çalışma ve alan yazındaki çalışmalara bakıldığında hakemlerin eğitim düzeyleri arttıkça problem çözme becerilerinin de arttığı görülmüştür.

Futbol, basketbol ve hentbol hakemlerinin HÖYÖ toplam puan, fiziksel yeterlik, oyun bilgisi, karar verme, baskı ve iletişim düzeyleri arasında eğitim durumlarına göre anlamlı bir fark olmadığı görülmüştür. Karaçam ve Pulur (2017b) çalışmanın paralelinde futbol, basketbol ve hentbol hakemlerinin HÖYÖ toplam puanı, fiziksel yeterlik, oyun bilgisi, karar verme, baskı, iletişim eğitim değişkenine göre anlamlı bir farklılık göstermediği sonucuna ulaşmışlardır. Bu durum eğitim düzeyinin hakemlerin öz yeterlikleri üzerinde etkili bir değişken olmadığı şeklinde yorumlanabilir.

Futbol, basketbol ve hentbol hakemlerinin problem çözme becerileri ile hakemlik branşları arasında anlamlı fark bulunamamıştır. Ekmekçi (2016b) basketbol ve voleybol hakemlerinin problem çözme becerilerini incelediği çalışmasında çalışmanın aksine basketbol hakemleri lehine anlamlı fark bulmuştur. Ekmekçi (2016b) bu farklılığın basketbol branşının kendine özgü özelliğinden kaynaklandığını belirtmiştir. Alan yazındaki bu farklı sonuçların çalışılan grubun kendine özgü özelliğinden kaynaklandığı düşünülmektedir.

Futbol, basketbol ve hentbol hakemlerinin HÖYÖ toplam puanı, fiziksel yeterlik, oyun bilgisi ve baskı alt boyutu ile hakemlik branşları arasında anlamlı farklılık bulunmuştur. Bu farkın hangi branşlar arasında olduğunu belirlemek için yapılan Tukey testi sonuçlarına göre futbol ve basketbol hakemlerinin hentbol hakemlerine göre öz yeterlik puanlarının daha yüksek olduğu görülmüştür. Fiziksel yeterlik alt boyutu puanlarında Futbol hakemleri hentbol hakemlerinden, basketbol hakemleri futbol ve hentbol hakemlerinden daha yüksek puan almışlardır. Karaçam ve Pulur (2017b) yaptıkları çalışmada çalışmanın paralelinde futbol ve basketbol hakemlerinin öz yeterliklerinin hentbol hakemlerine göre daha yüksek olduğu sonucuna ulaşmışlardır. Oyun bilgisi alt boyutu puanlarında basketbol hakemleri 
Karaçam, A., Pulur, A. (2019). Hakemlerin Problem Çözme Becerileri İle Öz Yeterlikleri Arasındaki İlişkinin İncelenmesi. Gaziantep Üniversitesi Spor Bilimleri Dergisi, 4(1), 115-130.

hentbol hakemlerinden daha yüksek puan almışlardır. Baskı alt boyutu puanlarında Futbol ve basketbol hakemleri hentbol hakemlerinden daha yüksek puan almışlardır. Karaçam ve Pulur (2017b) yaptıkları çalışmada çalışmanın aksine futbol, basketbol ve hentbol hakemlerinin oyun bilgisi ve baskı boyutlarında anlamlı fark olmadığı sonucuna ulaşmıştır. Karar verme ve iletişim puanları ile hakemlik branşları arasında anlamlı fark bulunamamıştır. Karaçam ve Pulur (2017b) yaptıkları çalışmada çalışmanın paralelinde futbol, basketbol ve hentbol hakemlerinin karar verme ve iletişim fark olmadığı sonucuna ulaşmıştır.

Futbol, basketbol ve hentbol hakemlerinin problem çözme becerileri ile yaşları ve hakemlik yılları arasında negatif yönlü ve anlamlı ilişki olduğu görülmüştür. Yaş ve hakemlik yılı arttıkça problem çözme envanterinden alınan puan düşmektedir. Bu durum yaş ve hakemlik yılı arttıkça hakemlerin problem çözme becerilerinin arttığı şeklinde yorumlanabilir. Ancak Karaçam ve Pulur (2016) basketbol hakemleri üzerine yaptıkları çalışmada çalışmanın aksine yaş ve hakemlik yılları ile hakemlerin problem çözme becerileri arasında anlamlı fark olmadığı sonucuna ulaşmışlardır. Alan yazındaki bu farklı durumun çalışılan hakem gruplarının kendine özgü yapısından ve ölçmedeki farklılıklardan kaynaklandığı düşünülmektedir.

Futbol, basketbol ve hentbol hakemlerinin HÖYÖ toplam puan, fiziksel yeterlik, oyun bilgisi, karar verme, baskı ve iletişim puanları ile yaş ve hakemlik yılları arasında pozitif yönlü ve anlamlı ilişki olduğu görülmüştür. Bu durum hakemlerin yaş ve hakemlik yılı arttıkça öz yeterlik ve öz yeterlik alt boyutlarından aldıkları puanların arttığı şeklinde yorumlanabilir. Yaş ile en yüksek ilişkinin HÖYÖ toplam puan arasında olduğu, en düşük ilişkinin ise baskı arasında olduğu görülmüştür. Hakemlik yılı ile en yüksek ilişkinin HÖYÖ toplam puan arasında olduğu, en düşük ilişkinin ise baskı arasında olduğu görülmüştür. Alan yazındaki çalışmalar incelendiğinde çalışmanın paralelinde yaş ve hakemlik yılı arttıkça hakemlerin öz yeterlik puanlarının arttığı sonuçlarına ulaşıImıştır (Karaçam ve Pulur, 2017a; Karaçam ve Pulur, 2017b; Karaçam ve Pulur, 2017c; Myers vd., 2012). Çalışma bu yönüyle alan yazındaki diğer çalışmalarla paralellik göstermektedir.

Futbol, basketbol ve hentbol hakemlerinin PÇE toplam ve HÖYÖ toplam, fiziksel yeterlik, oyun bilgisi, karar verme, baskı, iletişim, puanları arasındaki ilişkileri incelendiğinde; PÇE toplam puan ile HÖYÖ toplam puan fiziksel yeterlik, oyun bilgisi, karar verme, baskı ve iletişim değişkenleri negatif yönlü ve anlamlı ilişkili oldukları görülmektedir. PÇE ile en yüksek ilişkinin HÖYÖ toplam puan, en düşük ilişkinin ise 
Karaçam, A., Pulur, A. (2019). Hakemlerin Problem Çözme Becerileri İle Öz Yeterlikleri Arasındaki İlişkinin İncelenmesi. Gaziantep Üniversitesi Spor Bilimleri Dergisi, 4(1), 115-130.

baskı arasında olduğu görülmüştür. Bu durum HÖYÖ puanları artııça Hakemlerin problem çözme becerilerinin arttığı şeklinde yorumlanabilir. Yapılan ayrıntılı alan yazın taramasına rağmen hakemlerin öz yeterlikleri ile problem çözme becerileri arasındaki ilişkiyi inceleyen bir çalışmaya rastlanamamıştır. Çalışmanın bu yönüyle alan yazına katkı sağlayacağı düşünülmektedir.

Hakem öz yeterliği ile öz yeterliğin alt boyutları ve alt boyutların birbiriyle ilişkileri incelendiğinde tüm değişkenlerin birbiriyle pozitif yönlü ve anlamlı ilişkili olduğu görülmüştür. En yüksek ilişkinin HÖYÖ toplam puanı ile oyun bilgisi arasında olduğu, en düşük ilişkinin ise fiziksel yeterlik ile iletişim arasında olduğu görülmüştür. Alan yazındaki çalışmalar incelendiğinde çalışmanın paralelinde hakem öz yeterliği ile öz yeterliğin alt boyutları ve alt boyutların birbiriyle pozitif yönlü ve anlamlı ilişkili oldukları sonuçlarına ulaşılış̧ır (Adıgüzel, 2018; Karaçam ve Pulur, 2017a; Karaçam ve Pulur, 2017b; Karaçam ve Pulur, 2017c; Karaçam ve Adıgüzel, 2019; Myers vd., 2012). Çalışma bu yönüyle alan yazındaki diğer çalışmalarla paralellik göstermektedir.

Sonuç olarak, çalışmanın sonucunda Hakemlerin problem çözme becerilerinde eğitimin önemli bir değişken olduğu ve eğitim düzeyi arttıkça problem çözme beceri puanlarının arttığı görülmüştür. Futbol ve basketbol hakemlerinin hentbol hakemlerine göre öz yeterlik puanlarının daha yüksek olduğu görülmüştür. Fiziksel yeterlik alt boyutu puanlarında Futbol hakemleri hentbol hakemlerinden, basketbol hakemleri futbol ve hentbol hakemlerinden daha yüksek puan almışlardır. Oyun bilgisi alt boyutu puanlarında basketbol hakemleri hentbol hakemlerinden daha yüksek puan almışlardır. Baskı alt boyutu puanlarında Futbol ve basketbol hakemleri hentbol hakemlerinden daha yüksek puan almışlardır. Bu durum hakemlik branşının öz yeterlikte etkili bir değişken olduğunu göstermektedir. Futbol, basketbol ve hentbol hakemlerinin problem çözme becerileri ile yaşları ve hakemlik yılları arasında negatif yönlü; HÖYÖ toplam puan, fiziksel yeterlik, oyun bilgisi, karar verme, baskı ve iletişim puanları ile yaş ve hakemlik yılları arasında pozitif yönlü ve anlamlı ilişki olduğu görülmüştür. Bu durum hakemlerin yaş ve tecrübelerinin problem çözme becerilerinde ve öz yeterliklerinde önemli değişken olduğunu göstermektedir. PÇE toplam puan ile HÖYÖ toplam puan fiziksel yeterlik, oyun bilgisi, karar verme, baskı ve iletişim değişkenleri negatif yönlü, hakem öz yeterliği ile öz yeterliğin alt boyutları ve alt boyutlarının birbiriyle pozitif yönlü ve anlamlı ilişkili olduğu görülmüştür. Hakemlerin öz yeterliklerinin arttırılması problem çözme becerilerini, problem çözme 
Karaçam, A., Pulur, A. (2019). Hakemlerin Problem Çözme Becerileri İle Öz Yeterlikleri Arasındaki İlişkinin İncelenmesi. Gaziantep Üniversitesi Spor Bilimleri Dergisi, 4(1), 115-130.

becerilerinin arttııımasının da öz yeterliklerini arttıracağı görülmüştür. Bu nedenle hakem eğitim süreçleri planlanırken hakemlerin öz yeterlik ve problem çözme becerilerini geliştirmeye yönelik çalışmaların yapılmasının önemli olduğu düşünülmektedir.

\section{Kaynaklar}

Adıgüzel, N. S. (2018). Basketbol Hakemlerinin Fiziksel Öz Saygıları ile Öz Yeterlilikleri Arasındaki İlişkinin İncelenmesi. Ulusal Spor Bilimleri Dergisi, 2 (2), 129-137. DOI: $10.30769 /$ usbd.482410

Bandura, A. (1977). Self-efficacy: Toward a unifying theory of behavioral change. Psychological Review, 84 (2), 191-215.

Bandura, A. (1986). Social foundations of thought and action: A social cognitive theory. Englewood Cliffs, NJ: Prentice-Hall.

Bandura, A. (1997). Self-efficacy: The exercise of control. New York: Freeman.

Büyüköztürk, Ş. (2010). Bilimsel araştırma yöntemleri (5. Baskı). Ankara: Pegem Akademi.

Cel, A. (1994). Refereeing Psychology. Trns: KIN, A. Journal of Soccer Science and Technology, (1).

Efe, M., Öztürk, F., \& Koparan, Ş. (2008). Bursa İlindeki Faal Futbol Hakemlerinin Problem Çözme Ve Atılganlık Düzeylerinin Belirlenmesi. SPORMETRE Beden Eğitimi ve Spor BilimleriDergisi, 6(2), 49-59.

Ekmekçi, R. (2008). Basketbol hakemlerinin stres kaynakları ile stresle başa çıkma yöntemlerinin tesbiti ve önleyici yönetsel uygulamaların geliştirilmesi (Unpublished doctoral dissertation). Abant İzzet Baysal Üniversitesi, Bolu.

Ekmekçi, R. (2016a). Hakemlikte psikolojik hazırlık. Ankara: Detay Yayıncılık.

Ekmekci, R. (2016b). Determination of The Assertiveness and Problem Solving Skills of Basketball and Volleyball Referees. Pamukkale Journal of Sport Sciences, 7(3), 40-51.

Farshad, T., Esmaeili, M. R., \& Bavandpour, R. (2013). The effect of self-efficacy on job satisfaction of sport referees. European Journal of Experimental Biology, 3,2, 219-225.

Fraenkel, J. R., \& Wallen, N. E. (2009). How to design and evaluate research in education (7th ed.). New York: McGraw-Hill. 
Guillén, F., \& Feltz, D. L. (2011). A conceptual model of referee efficacy. Frontiers in psychology, 2, 25.

Hepler, T. J., \& Feltz, D. L. (2012). Take the first heuristic, self-efficacy, and decisionmaking in sport. Journal of Experimental Psychology: Applied, 18(2), 154-161. https://doi.org/10.1037/a0027807.

Heppner P. P., \& Petersen C. H. (1982). The Development and Implications of a Personal Problem-Solving Inventory. Journal of Counseling Psychology. 29 (1), 66-75

Karacam,A.,\& Adıguzel, N.S.(2019). Examining the relationship between referee performance and self-efficacy. European Journal of Educational Research, 8(1), 377-382.doi: 10.12973/eu-jer.8.1.377

Karaçam A. \& Pulur A. (2016). Identification the Relation between Active Basketball Classification Referees' Empathetic Tendencies and Their Problem Solving Abilities. Universal Journal of Educational Research, 4(8) 1912 - 1917. https://doi.org/10.13189/ujer.2016.040822

Karaçam, A. ve Pulur, A. (2017a). Hakem öz yeterlik ölçeği'nin (HÖYÖ) Türkçe'ye uyarlama çalışması. Ömer Halisdemir Üniversitesi Beden Eğitimi ve Spor Bilimleri Dergisi, 11(1), 118-128.

Karaçam, A., \& Pulur, A. (2017b). Examining the relationship between referee selfefficacy and general selfefficacy levels of football, basketball and handball referees. Universal Journal of Educational Research, 5, 9, 1571-1579. https://doi.org/10.11114/jets.v5i8.2450

Karaçam, A., \& Pulur, A. (2017c). Examining the relationship between referee selfefficacy and general selfefficacy levels of basketball referees in terms of certain variables. Journal of Education and Training Studies, 5(8), 37-45. https://doi.org/10.11114/jets.v5i8.2450

Karaçam, A, Pulur, A. (2018a). Hakemler İçin Mesleki Haz Ölçeği: Geçerlik ve Güvenirlik Çalışması-HİMHÖ. Gaziantep Üniversitesi Spor Bilimleri Dergisi, 3 (2), 35-45. DOI: 10.31680/gaunjss.416737

Karaçam, A., \& Pulur, A. (2018b). Basketbol Ve Futbol Hakemlerinin Mesleki Haz Düzeylerinin Bazı Demografik Değişkenler Açısından İncelenmesi. SPORMETRE Beden Eğitimi ve Spor Bilimleri Dergisi, 16(4), 288-295. doi: 10.1501/Sporm_0000000411 
Myers, N. D., Feltz, D. L., Guillén, F., \& Dithurbide, L. (2012). Development of, and initial validity evidence for, the Referee Self-Efficacy Scale: A multistudy report. Journal of sport and Exercise Psychology, 34(6), 737-765.

Sivrikaya, K. (2019). The Effects of Recreative Activities on Adjustment Levels of Young People. Asian Journal of Education and Training, 5(1): 25-30. doi: 10.20448/journal.522.2019.51.25.30

Spencer, B. D. (2015). Self-efficacy and Performance in Volleyball Referees. Michigan State University. Kinesiology.

Taylan, S.(1990). Studies of Adaptation, Validity and Reliability of Problem Solving Inventory of Heppner. Ankara University Institute of Social Sciences Master's Thesis, Ankara.

Tuero, C., Tabernero, B., Marquez, S., \& Guillen, F. (2002). Análisis de los factores que influyen en la práctica del arbitraje [Analysis of the factors affecting the practice of refereeing]. SCAPE, 1(1), 7-16.

Tutar, H. (2001). Professional Secretarial and Office Applications. Nobel Press Distribution. 1st Press, 221-233, Ankara 